\title{
Enraizamento de estacas de azaleia (Rhododendron simsii Planch.) no outono em AIB e diferentes substratos
}

\author{
Rooting of azalea cuttings (Rhododendron simsii Planch.) in the fall of AIB \\ and different substrates
}

\begin{abstract}
Alessandro Borini Lone ${ }^{\mathrm{I}}$ Lilian Keiko Unemoto ${ }^{\mathrm{I}}$ Lilian Yukari Yamamoto ${ }^{\mathrm{I}}$ Luciana Costa ${ }^{\mathrm{I}}$ Jeniffer Aparecida Schnitzer ${ }^{\mathrm{I}}$ Alessandro Jefferson Sato ${ }^{\mathrm{I}}$ Wilian da Silva Ricce ${ }^{\mathrm{I}}$ Adriane Marinho de Assis ${ }^{\mathrm{II}}$ Sérgio Ruffo Roberto ${ }^{\mathrm{III}}$
\end{abstract}

\section{RESUMO}

A azaleia é uma planta ornamental propagada comercialmente por meio de estacas, sendo difícil o seu o enraizamento em muitos casos, o que resulta em baixa produção de mudas. O objetivo do trabalho foi avaliar o uso do AIB e o efeito de diferentes substratos sobre o enraizamento de estacas herbáceas de azaleia no outono. O delineamento experimental foi o inteiramente casualizado, com cinco repetições, em um fatorial $2 \times 3$, sendo adotados os fatores: aplicação ou não de ácido indol butírico - AIB $\left(0 \mathrm{mg} \mathrm{L}^{-1} e\right.$ $1.000 \mathrm{mg} \mathrm{L}^{-1}$ ) e tipos de substratos (vermiculita - grânulos médios, casca de arroz carbonizada e fibra de coco). Após 76 dias, foram avaliadas as seguintes variáveis: retenção foliar (\%), estacas enraizadas (\%), sobrevivência das estacas (\%), comprimento da maior raiz, número de folhas, massa de matéria fresca das raízes por estaca, $\mathrm{pH}$ e condutividade elétrica dos substratos. Os resultados mostraram não haver diferenças para o enraizamento pela aplicação ou não de AIB. As estacas enraizadas em casca de arroz carbonizada $e$ vermiculita apresentaram número superior de folhas em relação às estacas do substrato fibra de coco. No entanto, a fibra de coco e a casca de arroz carbonizada proporcionaram um maior comprimento de raiz. Para massa de matéria fresca por estaca, a fibra de coco também apresentou o melhor resultado. Não houve contribuição do AIB no enraizamento de estacas de azaleia, e o substrato fibra de coco foi o que apresentou melhor desempenho para o enraizamento das estacas.

Palavras-chave: estaquia, auxina, produção de mudas, fibra de coco.

\begin{abstract}
Azalea is an ornamental plant commercially propagated by cuttings, and their rooting process in many cases, is difficult, which results in decreased production of seedlings. The objective of this study was to evaluate the use of IBA and the effect of different substrates on the rooting of cuttings of azalea in the fall. A randomized design with five replications in a factorial array was used as a statistical model, and it was adopted the following factors: types of substrates (vermiculite - medium granules, hull rice coal and coconut fiber), and indole butyric acid - IBA (0mg L $\mathrm{L}^{-1}$ and 1,000mg $\left.\mathrm{L}^{-1}\right)$. After 76 days, the following variables were evaluated: leaf retention (\%), rooted cuttings (\%), cuttings survival (\%), length of the longest root, number of leaves, fresh weight of roots per cutting, $\mathrm{pH}$ and electrical conductivity of the substrates. There was no difference of using IBA to improve rooting. The hull rice coal and vermiculite substrates resulted in a higher number of leaves on cuttings than coconut fiber. However, the coconut fiber and hull rice coal provided a greater root length. For fresh weight of roots per cutting, the coconut fiber also provided the best results. It was concluded that there was no contribution of IBA on the rooting of azalea, and coconut fiber substrate was more suitable for its rooting.
\end{abstract}

Key words: cutting, auxin, production of seedlings, coconut fiber.

'Programa de Pós-graduação em Agronomia, Universidade Estadual de Londrina (UEL), CP 6001, 86051-990, Londrina, PR, Brasil.

IIPrograma Nacional de Pós-doutorado, Centro de Ciências Agrárias (CCA), UEL, Londrina, PR, Brasil.

III Departamento de Agronomia, UEL, CP 6001, 86051-990, Londrina, PR, Brasil. E-mail: sroberto@uel.br. Autor para correspondência. 


\section{INTRODUÇÃO}

A azaleia é uma planta ornamental originária da China, pertencente à família Ericaceae, muito cultivada no Brasil, em jardins e interiores, em razão do efeito decorativo de suas flores, sendo formada por hibridação e melhoramento (LORENZI \& SOUZA, 1995). Sua propagação é realizada comercialmente por meio de estacas (CLARKE, 1982). Entretanto, em muitos casos, a porcentagem de enraizamento dessa planta é baixa, resultando em baixa produção de mudas (CHALFUN et al., 1997). Segundo LEE (1965), o enraizamento das estacas está relacionado ao tipo da espécie a ser cultivada, bem como às condições do ambiente em que são conduzidas, tais como: tipo de substrato, umidade, temperatura, irrigação e luminosidade. ZUFFELLATO-RIBAS \& RODRIGUES (2001) destacam ainda a importância das auxinas na formação de raízes de estacas.

O substrato, meio onde se desenvolvem as raízes das plantas cultivadas fora do solo (KÄMPF et al., 2006), pode interferir no processo de enraizamento das estacas (FACHINELLO et al., 2005) e exerce influência na qualidade das raízes formadas e no percentual de enraizamento. Entre os materiais comumente usados estão a vermiculita, a casca de arroz carbonizada e a fibra de coco. Devido à elevada porosidade e boa retenção de umidade, a vermiculita é cada vez mais utilizada como substrato para enraizamento de estacas herbáceas e semilenhosas (GONÇALVES \& MINAMI, 1994; FACHINELLO et al., 2005). A casca de arroz carbonizada é um substrato que possui elevada porosidade e resistência à decomposição, sem riscos de falta de oxigênio para as raízes, baixa densidade e alta permeabilidade à água, conferindo ao substrato maior aeração e drenagem. A fibra de coco se destaca pelas boas propriedades físicas, como a não reação com os nutrientes da adubação, longa durabilidade sem alterações das características físicas, possibilidade de esterilização e abundância da matéria-prima, que é renovável (CARRIJO et al., 2002; KAMPF et al., 2006; FARIA et al., 2010).

Além do substrato, o processo de formação de raízes em estacas pode estar relacionado também com o regulador de crescimento. Entre estes, a auxina natural, produzida nas folhas e nas gemas, move-se naturalmente para a parte inferior da planta, aumentando sua concentração na base do corte, junto com os açúcares e outras substâncias nutritivas. Em muitas plantas ornamentais, o enraizamento é maximizado pela aplicação de auxinas como em Malvaviscus arboreus (LOSS et al., 2009), Allamanda cathartica (LOSS et al., 2008), Jasminum mesnyi (ALTHAUS et al., 2007) e Chrysanthemum morifolium (CUQUEL et al., 1992).

O ácido indolbutírico (AIB) é provavelmente a principal auxina sintética de uso geral porque não é tóxica para a maioria das plantas, mesmo em altas concentrações. Além disso, é bastante efetiva para um grande número de espécies e relativamente estável, sendo pouco suscetível à ação dos sistemas de enzimas de degradação de auxinas (PIRES \& BIASI, 2003).

Pelo exposto, considerando o potencial da azaleia como planta ornamental e a necessidade de otimizar as técnicas de propagação que permitem a manutenção das características genéticas desejáveis, o objetivo do trabalho foi avaliar o enraizamento de estacas herbáceas de azaleia no outono, em diferentes substratos e com utilização ou não de AIB.

\section{MATERIAL E MÉTODOS}

O estudo foi realizado em casa de vegetação, na Universidade Estadual de Londrina (UEL), no Paraná, localizada a $23^{\circ} 23^{\prime} \mathrm{S}$ e $51^{\circ} 11^{\prime} \mathrm{W}$ e altitude média de $560 \mathrm{~m}$, no período de abril a junho de 2009. Segundo a classificação de Köppen, o clima da região é do tipo Cfa (subtropical úmido).

Foram utilizadas estacas herbáceas de $12 \mathrm{~cm}$ da parte mediana dos ramos de plantas matrizes de azaleia pertencentes à coleção de plantas ornamentais da UEL. Antes de efetuar a coleta das estacas, foi preparada a solução hidroalcoólica do AIB, sendo pesado 0,1g de AIB em balança semianalítica e dissolvido em 50mL de álcool, em um Becker, com auxílio de agitador eletromagnético. Após totalmente dissolvido, completou-se o volume para $100 \mathrm{~mL}$ com água destilada, obtendo-se então a concentração de $1.000 \mathrm{mg} \mathrm{L}^{-1}$ de AIB.

O preparo das estacas consistiu em um corte em bisel logo abaixo de um nó com a eliminação das folhas da parte basal, deixando-se um par de folhas na parte superior. Durante o preparo das estacas, estas foram dispostas provisoriamente em um recipiente com água para evitar a desidratação. Após o seu preparo, as estacas foram submetidas à aplicação de AIB, por meio de imersão rápida (dez segundos) da sua porção basal. Em seguida, as estacas foram imediatamente colocadas para enraizamento em caixas plásticas (com as dimensões $44 \times 30 \times 7 \mathrm{~cm}$ ), contendo os substratos em câmara de nebulização, com regime intermitente controlado por temporizador e válvula solenoide programada para nebulizar as estacas durante um minuto a cada 
intervalo de 10 minutos. O bico nebulizador empregado (Modelo Mist Dan Sprinklers, Israel) apresenta vazão de $35 \mathrm{~L} \mathrm{hora}^{-1}$. A câmara de nebulização encontra-se instalada em estufa com cobertura de filme de polietileno transparente e sombrite $30 \%$. Foi realizada, semanalmente, adubação foliar com $5 \mathrm{~mL} \mathrm{~L}^{-1}$ do fertilizante comercial Biofert Plus $^{\circledR}$ (8-9-9 + micronutrientes).

O delineamento experimental foi $o$ inteiramente casualizado, com cinco repetições, em um fatorial $2 \times 3$, sendo os fatores a aplicação ou não de AIB (0 e $\left.1.000 \mathrm{mg} \mathrm{L}^{-1}\right)$ e três tipos de substratos (vermiculita de granulação média, casca de arroz carbonizada e fibra de coco), e cada parcela foi composta por 10 estacas. Para o controle de doenças fúngicas, as estacas foram tratadas semanalmente com fungicida sistêmico.

Após 76 dias, foram avaliados a porcentagem de retenção foliar, a porcentagem de estacas enraizadas, a porcentagem de sobrevivência das estacas, o comprimento da maior raiz $(\mathrm{cm})$, o número de folhas e a massa de matéria fresca das raízes por estaca $(\mathrm{g})$. Também foram avaliados nesse período o $\mathrm{pH}$ e a condutividade elétrica $\left(\mu \mathrm{S} \mathrm{cm}^{-1}\right)$ dos substratos, segundo KAMPF et al. (2006). Os dados foram submetidos à análise de variância, e as médias comparadas pelo teste de Tukey, a 5\% de probabilidade.

\section{RESULTADOS E DISCUSSÃO}

Para porcentagem de sobrevivência das estacas e retenção foliar, foram obtidos valores de $100 \%$, independentemente da utilização de AIB e do substrato utilizado. Com relação à porcentagem de estacas enraizadas, não houve interação significativa entre as concentrações de AIB e os tipos de substratos, com médias entre 96 e 99\% (dados não tabelados).

Em experimento com estacas de azaleia, CARVALHO et al. (2002) não verificaram diferenças na porcentagem de sobrevivência, sendo utilizados ácido naftaleno acético (ANA) e vermiculita, enquanto FERRIANI et al. (2006) não observaram diferenças significativas para a porcentagem de estacas enraizadas de Rhododendron thomsonii em vermiculita e diferentes concentrações e formas de aplicação de AIB. SALVADOR et al. (2005) também concluíram que não houve diferença entre doses de AIB e fixador no enraizamento de estacas de azaleia da cultivar 'Terra Nova', sendo utilizados vermiculita e casca de etenos como substrato.

Quanto ao número de folhas, não foi observada diferença significativa entre as concentrações de AIB; porém, no substrato fibra de coco, as estacas apresentaram menor número de folhas em relação às estacas dos substratos casca de arroz carbonizada e vermiculita, que não apresentaram diferenças entre si (Tabela 1). MAUAD et al. (2004) citaram que a presença de folhas contribuiu para o enraizamento das estacas de azaleia. HARTMANN et al. (1997) afirmaram que a presença de folhas nas estacas influencia o enraizamento, sendo as auxinas muito importantes nesse processo, uma vez que é produzida nas folhas novas e nas gemas, movendo-se naturalmente para a parte inferior da planta e acumulando-se na base do corte, junto com açúcares e outras substâncias nutritivas.

Para o comprimento da maior raiz, não foi verificada diferença entre as concentrações de AIB testadas (Tabela 1). Embora o efeito positivo no uso da auxina seja relatado por alguns autores (ONO \& RODRIGUES, 1996; MAUAD et al., 2004), GALLE (1995) cita que o uso de reguladores vegetais não foi

Tabela 1 - Número médio de folhas por estaca, comprimento da maior raiz $(\mathrm{cm})$ e massa de matéria fresca por estaca (g) de azaleia (Rhododendron simsii) submetida aos substratos CAC (Casca de arroz carbonizada), VEM (Vermiculita - grânulos médios) e FCOCO (Fibra de coco) e às concentrações de AIB, em câmara de nebulização, aos 76 dias da instalação do experimento.

\begin{tabular}{lccc}
\hline Concentrações de AIB $\left(\mathrm{mg} \mathrm{L}^{-1}\right)$ & Número de folhas por estaca & Comprimento da maior raiz (cm) & Massa de matéria fresca por estaca (g) \\
\hline 0 & $10,5 \mathrm{a}^{*}$ & $3,6 \mathrm{a}$ & $0,51 \mathrm{a}$ \\
1.000 & $10,6 \mathrm{a}$ & $3,8 \mathrm{a}$ & $0,52 \mathrm{a}$ \\
Média & 10,6 & 3,7 & 0,52 \\
Substratos & & & $0,39 \mathrm{~b}$ \\
CAC & $11,2 \mathrm{a}$ & $3,9 \mathrm{a}$ & $0,45 \mathrm{~b}$ \\
VEM & $12,6 \mathrm{a}$ & $2,8 \mathrm{~b}$ & $0,71 \mathrm{a}$ \\
FCOCO & $7,9 \mathrm{~b}$ & $4,4 \mathrm{a}$ & 0,52 \\
Média & 10,57 & 3,7 & 32,44 \\
CV $(\%)$ & 12,77 & 13,87 & \\
\hline
\end{tabular}

*Médias não seguidas das mesmas letras nas colunas diferem entre si pelo Teste de Tukey, a 5\% de significância. 
essencial no enraizamento da maior parte das cultivares de azaleia; fato verificado por CARVALHO et al. (2002) e FERRIANI et al. (2006), que não observaram diferenças significativas nos tratamentos com ANA e AIB, respectivamente. $O$ fato de as estacas de azaleias enraizarem sem a presença de AIB pode ser atribuído à presença de folhas nas estacas (CARVALHO et al., 2002).

De acordo com PEREIRA et al. (2005), a melhor taxa de enraizamento pode estar relacionada ao melhor contato das partículas do substrato com a base das estacas. Em relação aos substratos testados, a casca de arroz carbonizada e a fibra de coco proporcionaram maior comprimento de raiz nas estacas em relação à vermiculita, que apresentou a menor média. MAUAD et al. (2004) também relataram que a casca de arroz carbonizada foi o substrato que proporcionou o maior comprimento em raízes de azaleia, provavelmente, em função da menor densidade e maior porcentagem de macroporos, o que facilitaria o escoamento do excesso de água, favorecendo o desenvolvimento radicular. Da mesma forma, ARAUJO et al. (2007), testando substratos na aclimatização de um híbrido de Cattleya loddgesii "Alba" x Cattleya loddgesii "Atibaia", obtiveram maior comprimento de raízes usando a casca de arroz carbonizada e fibra de piaçava. PIO et al. (2005) citaram que a fibra de coco foi um dos substratos que proporcionou melhor enraizamento de estacas herbáceas de figueira (Ficus carica L.) devido ao seu maior espaço de aeração.

Quanto à massa de matéria fresca de raízes (Tabela 1), não houve influência do uso de AIB. Entretanto, em relação aos substratos, a maior média foi obtida nas estacas enraizadas em fibra de coco, diferindo estatisticamente dos demais substratos.
O substrato, sendo o local onde as estacas estão fixadas, torna-se fonte de suprimento de água e nutrientes, em que estão localizados os fatores estimulantes do enraizamento (PEREIRA et al., 2005). Dessa forma, a variação nos valores de $\mathrm{pH}$ exerce influência no metabolismo na base das estacas, estimulando ou inibindo processos enzimáticos que favoreçam a desdiferenciação e diferenciação de células-alvo, que responderão ao estímulo, originando os primórdios radiculares.

Observou-se que houve interação significativa entre as concentrações de AIB e os tipos de substratos em relação ao pH destes (Tabela 2). As maiores médias foram verificadas no tratamento com fibra de coco sem imersão das estacas em AIB e na casca de arroz carbonizada, em que se aplicou AIB (1.000 $\mathrm{mg} \mathrm{L}^{-1}$ ). Segundo KÄMPF et al. (2006), a faixa de $\mathrm{pH}$ recomendada para o cultivo de azaleia está entre 4,5 e 4,8; entretanto, embora os valores obtidos tenham sido superiores, não houve interferência no processo de enraizamento das estacas. Tal fato pode ter ocorrido em função do curto período (76 dias) em que as estacas permaneceram no leito de enraizamento.

Quanto à condutividade elétrica, não houve interação significativa entre doses de AIB e tipos de substratos (Tabela 2). No entanto, houve diferença estatística significativa entre os substratos, e a casca de arroz carbonizada apresentou média superior à vermiculita (162,30 e $144,40 \mu \mathrm{S} \mathrm{cm}^{-1}$ respectivamente); não diferindo estatisticamente da fibra de coco $\left(155,70 \mu \mathrm{S} \mathrm{cm}^{-1}\right)$. Ressalta-se, porém, que todos os valores estão classificados como ideais para substratos de sementeiras e mudas em bandejas, segundo BALLESTER-OLMOS (1993), que descreve que valores entre $75-200 \mu \mathrm{S} \mathrm{cm}^{-1}$ são ideais para sementeiras e mudas em bandejas; $200-350 \mu \mathrm{S} \mathrm{cm}^{-1}$ são

Tabela 2 - Médias de pH e condutividade elétrica dos substratos CAC (Casca de arroz carbonizada); VEM (Vermiculita- grânulos médios) e FCOCO (Fibra de coco), aos 76 dias da instalação do experimento.

\begin{tabular}{|c|c|c|c|c|c|c|}
\hline \multirow{3}{*}{ Substratos } & \multicolumn{3}{|c|}{$\mathrm{pH}$} & \multicolumn{3}{|c|}{ Condutividade elétrica $\left(\mu \mathrm{S} \mathrm{cm}^{-1}\right)$} \\
\hline & --------A & $\left.{ }^{1}\right)-------\cdot$ & & -----------AIB & ---------- & \multirow[b]{2}{*}{ Médias } \\
\hline & 0 & 1000 & Médias & 0 & 1000 & \\
\hline $\mathrm{CAC}$ & $7,04 \mathrm{bB} *$ & $7,47 \mathrm{aA}$ & $7,26 \mathrm{~A}$ & $160,00 n s^{* *}$ & 164,60 & $162,30 \mathrm{~A}$ \\
\hline VERM & $7,03 \mathrm{aB}$ & $6,98 \mathrm{aB}$ & $7,00 \mathrm{~B}$ & 143,80 & 145,00 & $144,40 \mathrm{~B}$ \\
\hline FCOCO & $7,39 \mathrm{aA}$ & $7,04 \mathrm{aB}$ & $7,21 \mathrm{~A}$ & 159,00 & 152,40 & $155,70 \mathrm{AB}$ \\
\hline Médias & $7,15 \mathrm{a}$ & $7,16 \mathrm{a}$ & & $154,27 \mathrm{~A}$ & $154,00 \mathrm{a}$ & \\
\hline $\mathrm{CV}(\%)$ & 0,89 & & & 9,85 & & \\
\hline
\end{tabular}

*Médias não seguidas das mesmas letras minúsculas nas linhas e maiúsculas nas colunas diferem entre si pelo teste de Tukey, a 5\% de significância.

**Não significativo. 
apropriados para a maioria das plantas e acima de $350 \mu \mathrm{S} \mathrm{cm}^{-1}$ são classificados como elevados.

A estaquia herbácea de azaleia é viável no período do outono, devendo ser realizada em ambiente com nebulização controlada, por propiciar melhor aproveitamento do material propagativo e maior eficiência na multiplicação de mudas. Entre os substratos testados, a fibra de coco é o mais indicado.

\section{CONCLUSÃO}

A propagação de azaleia pode ser efetuada no período do outono, e o uso de AIB não exerce influência sobre o enraizamento de estacas herbáceas, sendo a fibra de coco o substrato mais indicado.

\section{AGRADECIMENTOS}

Ao Conselho Nacional de Desenvolvimento Científico e Tecnológico (CNPq) e à Coordenação de Aperfeiçoamento de Pessoal de Nível Superior (CAPES), pela concessão de bolsa aos autores.

\section{REFERÊNCIAS}

ARAUJO, A.G. et al. Substratos alternativos ao xaxim e adubação de plantas de orquídea na fase de aclimatização. Ciência Rural, Santa Maria, v.37, n.2, p.569-571, 2007. Disponível em: <http://www.scielo.br/scielo.php?pid=S0103$84782007000200044 \&$ script $=$ sci_arttext\&tlng $=\mathrm{es}>$. Acesso em: 20 jul. 2009 . doi: 10.1590/S0103-84782007000200044.

ALTHAUS, M.M. et al. Influência do ácido naftaleno acético e dois tipos de substrato no enraizamento de estacas de jasmimamarelo. Revista Ciência Agronômica, Maringá, v.38, n.3, p.322-326, 2007. Disponível em: < http:// www.ccarevista.ufc.br/seer/index.php/ccarevista/article/view/ 123/118>. Acesso em: 27 jul. 2009.

BALLESTER-OLMOS, J.F. Substratos para el cultivo de plantas ornamentales. Madrid: Saijen,1993. 44p.

CARRIJO, O.A. et al. Fibra da casca do coco verde como substrato agrícola. Horticultura Brasileira, Campinas, v.20, n.4, p.533-535, 2002. Disponível em: < http:// w w w. s c i e 1 o.br/s c i e 1 o.ph p ? p i d = S 0102 $05362002000400003 \&$ script $=\mathrm{sci}$ arttext\&tlng $=\mathrm{es}>$. Acesso em: 23 jul. 2009. doi: 10.1590/S0102-05362002000400003.

CARVALHO, D.B. et al. Indução de raízes em estacas semilenhosas de azaléia através da aplicação de ácido naftalenoacético em solução. Scientia Agraria, Curitiba, v.3, n.1-2, p.97-101, 2002. Disponível em: < http://www.gepe.ufpr.br/ pdfs/Azaleia\%20estaquia.pdf>. Acesso em: 23 jul. 2009.

CHALFUN, N.N. et al. Efeito da auxina e do anelamento no enraizamento de estacas semilenhosas de azaléias. Ciência e Agrotecnologia, Lavras, v.21, n.4, p.516-520, 1997.

CLARKE, J.H. Gentting started with rhododendrons and azaleas. Portaland: Timber, 1982. 268p.
CUQUEL, F. et al. Avaliação do enraizamento de estacas de crisântemo (Chrysanthemum morifolium L.) cv. white reagan 606 tratadas com ácido indolbutírico (IBA). Scientia Agricola, Piracicaba, v.49, n.1, p.15-22, 1992. Disponível em: < http:// www.scielo.br/scielo.php? script=sci_arttext\&pid=S0103$90161992000400004 \& \operatorname{lng}=\mathrm{en} \& \mathrm{nrm}=\mathrm{iso} \& \mathrm{t} \operatorname{lng}=\mathrm{pt}>$. Acesso em: 23 maio, 2009. doi: 10.1590/S0103-90161992000400004.

FACHINELlO, J.C. et al. Propagação de plantas frutíferas. Brasília: Embrapa Informações Tecnológicas, 2005. 221p.

FARIA, R.T. et al. Cultivo de orquídeas. Londrina: Mecenas, 2010. 208p.

FERRIANI, A.P. et al. Propagação vegetativa de estaquia de azaléia arbórea (Rhododendron Thomsonii HOOK. f.). Semina: Ciências Agrárias, Londrina, v.27, n.1, p.35-42, 2006 .

GAlle, F.C. Azaleas. Portland: Timber, 1995. 519p. Disponível em: < http://www.uel.br/revistas/uel/index.php/ semagrarias/article/viewArticle/2397>. Acesso em: 10 jun. 2009.

GONÇALVES, A.L.; MINAMI, K. Efeito de substrato artificial no enraizamento de estacas de calanchoe (kalanchoe $\boldsymbol{x}$ blossfeldiana cv. SINGAPUR, Crassulaceae). Revista da Sociedade da Agricultura, Rio de Janeiro, v.51, n.2, p.240244, 1994. Disponível em: <http://www.scielo.br/ s cie lo.php? script=sci_arttext\&pid=S 0103 $90161994000200007 \& \operatorname{lng}=\mathrm{en} \& \mathrm{nrm}=\mathrm{iso} \& \mathrm{t} \operatorname{lng}=\mathrm{pt}>$. Acesso em: 16 jun. 2009. doi: 10.1590/S0103-90161994000200007.

HARTMANN, H.T. et al. Plant propagation: principles and practices. 6.ed. New York: Englewood Clipps/Prentice Hall, 1997. 770p.

KAMPF, A.N. et al. Floricultura: técnicas de preparo de substratos. Brasília: LK, 2006. 132p.

LEE, J.D. The azalea book. Tailandia: [s.n.], 1965. 461p.

LORENZI, H.; SOUZA, H.M. Plantas ornamentais no Brasil: arbustivas, herbáceas e trepadeiras. Nova Odessa/SP: Plantarum, 1995. 720p.

LOSS, A. et al. Enraizamento de estacas de Allamanda cathartica L. tratadas com ácido indolbutírico (AIB). Revista Brasileira de Ciências Agrárias, Pernambuco, v.3, n.4, p.313-316, 2008. Disponível em: < http://www.agraria.pro.br/ sistema/index.php?journal=agraria \&page $=$ article $\&$ op $=$ viewFi le\&path $\% 5 \mathrm{~B} \% 5 \mathrm{D}=329 \&$ path $\% 5 \mathrm{~B} \% 5 \mathrm{D}=221>$. Acesso em: 25 jun. 2009.

LOSS, A. et al. Indução do enraizamento em estacas de Malvaviscus arboreus Cav. com diferentes concentrações de ácido indol-butírico (AIB). Acta Scientiarum Agronomy, Maringá, v.31, n.2, p.269-273, 2009. Disponível em: < http:/ /periodicos.uem.br/ojs/index.php/ActaSciAgron/article/view/ 799/799> . Acesso em: 10 jun. 2009. doi: 10.4025/ actasciagron.v31i2.799.

MAUAD, M. et al. Enraizamento de estacas de azaléia tratadas com concentrações de ANA em diferentes substratos. Ciência e Agrotecnologia, Lavras, v.28, n.4, p.771-777, 2004. 
Disponível em: < http://www.editora.ufla.br/site/_adm/upload/ revista/28-4-2004_07.pdf>. Acesso em: 27 jun. 2009.

ONO, E.O.; RODRIGUES, J.D. Aspecto da fisiologia do enraizamento de estacas caulinares. Jaboticabal: UNESP, 1996. $83 p$

PEREIRA, M. et al. Efeitos de substratos, valores de $\mathrm{pH}$, concentrações de AIB no enraizamento de estacas apicais de jabuticabeira [Myrciaria jabuticaba (Vell.) O. Berg.]. Scientia Forestalis, Piracicaba, n.69, p.84-92, 2005. Disponível em: $<$ http://www.lcb.esalq.usp.br/publications/articles/2005/ sfV69.pdf>. Acesso em: 27 maio, 2009

PIO, R. et al. Substratos no enraizamento de estacas herbáceas de figueira oriundas da desbrota. Ciência e Agrotecnologia, Lavras, v.29, n.3, p.604-609, 2005. Disponível em: < http:/ /www.scielo.br/scielo.php?script $=$ sci_arttext\&pid $=$ S1413-
$70542005000300014 \& \operatorname{lng}=\mathrm{en} \& \mathrm{nrm}=\mathrm{iso} \& \mathrm{t} \operatorname{lng}=\mathrm{pt}>$. Acesso em: 27 jun. 2009. doi: 10.1590/S1413-70542005000300014.

PIRES, E.J.P.; BIASI, L.A. Propagação da videira. In: POMMER, C.V. Uva: tecnologia da produção, póscolheita e mercado. Porto Alegre: Cinco Continentes, 2003. p. 295-350.

SALVADOR, E.D. et al. Enraizamento de estacas de azaléia Rhododendron indicum: cultivar terra nova tratadas com ácido indolbutírico, com o uso ou não de fixador. Ambiência, Guarapuava, v.1, n.1, p.21-24, 2005. Disponível em: < http:/ /revistas.unicentro.br/index.php/ambiencia/article/view/120/ 126>. Acesso em: 20 jun. 2009.

ZUFFELLATO-RIBAS, K.C.; RODRIGUES, J.D. Estaquia: uma abordagem dos principais aspectos fisiológicos. Curitiba: UFPR, 2001. 39p. 